\title{
EXISTENCE AND MULTIPLICITY OF SOLUTIONS FOR KIRCHHOFF TYPE PROBLEMS WITH PARAMETER
}

\author{
WEI TANG AND WEIBING WANG
}

Abstract. In this paper, we study Kirchhoff type problems with parameter on a bounded domain. By using variational methods, we prove the existence and multiplicity of weak solutions.

Mathematics subject classification (2010): 35J60, 35J25.

Keywords and phrases: Kirchhoff type equation, weak solution, critical point.

\section{REFERENCES}

[1] C. O. Alves, F. J. S. A. CorrêA, T. F. MA, Positive solutions for a quasilinear elliptic equation of Kirchhoff type, Comput. Math. Appl., 49, (1) (2005), 85-93.

[2] C. CHEN, Y. KuO, T. WU, The Nehari manifold for a Kirchhoff type problem involving sign-changing weight functions, J. Diffrential Equations, 250 (2011), 1876-1908.

[3] B. CHENG, New existence and multiplicity of nontrivial solutions for nonlocal elliptic Kirchhoff type problems, J. Math. Anal. Appl., 394 (2012), 488-495.

[4] B. Cheng, X. Wu, Existence results of positive solutions of Kirchhoff type problems, Nonlinear Anal., 71, (10)(2009), 4883-4892.

[5] B. CHENG, X. WU, J. LIU, Multiplicity of nontrivial solutions for Kirchhoff type problems, Boundary Value Problems 2010, 2010:1.

[6] F. JÚLIo, S. A. CorrêA ANd G.M. FigueIredo, On an elliptic equation of p-Kirchhoff type via variational methods, Bull. Austral. Math. Soc., 74 (2006), 263-277.

[7] F.FARACI, R.LIVERA,Bifurcation theorems for nonlinear problems with lack of compactness, Ann. Pol. Math., 82 (2003), 77-85.

[8] X. HE, W. Zou, Existence and concentration behavior of positive solutions for a Kirchhoff equation in $\mathbb{R}^{3}$, J. Differential Equations, 252, (2) (2012), 1813-1834.

[9] J. JIN, X. WU, Infinitely many radial solutions for Kirchhoff-type problems in $\mathbb{R}^{N}$, J. Math. Anal. Appl., 369, (2) (2010), 564-574.

[10] J.F. LIAO, P. ZHANG, J. LIU, C.L. TANG, Existence and multiplicity of positive solutions for a class of Kirchhoff type problems with singularity, J. Math. Anal. Appl., 430 (2015), 1124-1148.

[11] C. LIU, J. WANG, Q. GAO, Existence of nontrivial solutions for p-Kirchhoff type equations, Boundary value problems 2013, 2013:279.

[12] J. L. LiOns, On some equations in boundary value problems of mathematical physics, Contemporary Developments in Continuum Mechanics and Partial Differential equations (Proc. Internat. Sympos., Inst. Mat., Univ. fed. Rio de Janeiro, Riio de Janeiro, 1977), pp. 284-346. North-Holland Math. Stud., vol. 30, North-Holland, Amsterdam(1978)

[13] R. MA, G. DAI, C. GAO, Existence and multiplicity of positive solutions for a class of $p(x)$-Kirchhoff type equations, Boundary Value Problems, (2012), 2012:1-16.

[14] A. MAO, Z. ZHANG, Sign-changing and multiple solutions of Kirchhoff type problems without the P.S. condition, Nonlinear Anal., 70, (3) (2009), 1275-1287.

[15] K. Perera, Z. Zhang, Nontrivial solutions of Kirchhoff-type problems via the Yang-index, J. Differential Equations, 221, (1) (2006), 246-255.

[16] B. RiCCERI, A general variational principle and some of its applications, J. Comput. Appl. Math., 113 (2000), 401-410. 
[17] B. RICCERI, On a classical existence theorem for nonlinear elliptic equations, in Experimantal, constructive and nonlinear alalysis, M.Thra ed., 275-278, CMS Conf. Proc. 27, Canad. Math. Soc., 2000.

[18] B. RICCERI, A bifurcation theory for some nonlinear elliptic equations, Colloq. Math., 95 (2003), $139-151$.

[19] B. RICCERI, A further refinement of a three critical points theorem, Nonlinear Anal., 74 (2011), $7446-$ 7454

[20] J.J. Sun, C.L. TANG, Existence and multiplicity of solutions for Kirchhoff type equations, Nonlinear Anal., 74 (4), (2011), 1212-1222.

[21] J. Sun, S. LiU, Nontrivial solutions of Kirchhoff type problems, Appl. Math. Lett., 25, (3) (2012), $500-504$.

[22] L. WEI, X. HE, Multiplicity of high energy solutions for superlinear Kirchhoff equations, J. Appl. Math. Comput., 39, (1-2) (2012), 473-487.

[23] J. Sun, On some problems about nonlinear operators, Ph.D.Thesis, Shandong University, Jinan, 1984.

[24] W. SHUAI, Sign-changing solutions for a class of Kirchhoff-type problem in bounded domains, J. Differential Equations, 259 (2015), 1256-1274.

[25] Y. YANG, J. H. ZHANG, Nontrivial solutions of a class of nonlocal problems via local linking theory, Appl. Math. Lett., 23 (2010), 377-380.

[26] Y. YE, Infinitely many solutions for Kirchhoff type problems, Differ. Equ. Appl., 5, (1) (2013), 83-92. 